\title{
Experimental chimaerism in sheep
}

\author{
Carole B. Fehilly, S. M. Willadsen and Elizabeth M. Tucker \\ A.R.C. Institute of Animal Physiology, Animal Research Station, 307 Huntingdon Road, \\ Cambridge CB3 OJQ, U.K.
}

\begin{abstract}
Summary. Composite sheep embryos $(N=110)$ were produced by aggregation of blastomeres from 2-, 4- or 8-cell embryos. Each composite embryo consisted of equal numbers of blastomeres from 2-8 parent embryos, the total cell number ranging from one quarter of the normal cell number to 8 times the normal cell number. The embryos were embedded in agar and transferred to ligated sheep oviducts to allow development up to the early blastocyst stage. Of the 101 embryos subsequently recovered, 77 had formed normally organized blastocysts and 74 of these were transferred to 51 recipients. Thirty-eight recipients went to full term, producing a total of 53 lambs. Of the 48 lambs which survived to be blood typed at 60 days of age, 36 were judged to be chimaeric on the basis of their blood type and/or on the basis of external features. The proportion of chimaeras was larger amongst the lambs produced from composite embryos of the normal number of cells or more $(25 / 26)$ than amongst lambs produced from composite embryos of less than the normal cell number $(11 / 22)$.
\end{abstract}

\section{Introduction}

Chimaeric embryos have been invaluable in the study of developmental mechanisms in the mouse (see McLaren, 1976). Such studies should be extended to other species to provide a broader basis for our understanding of mammalian development. This is of particular interest in the large domestic species, as it may offer keys to controlled manipulation of early embryonic development. So far, however, there have been only few reports of experimental chimaeras being produced by manipulation of embryos in a large domestic species (sheep: Pighills, Hancock \& Hall, 1968; Tucker, Moor \& Rowson, 1974). In all instances the success rate achieved has been low. The main reason for the relative failure of attempts to produce sheep chimaeras by blastomere aggregation, compared to the apparent ease with which mouse chimaeras may be produced by this approach (Tarkowski, 1961; Mintz, 1971), has been the lack of adequate methods for culture in vitro of cleaving sheep embryos combined with the inability of these young embryos to survive in vivo in the absence of an intact zona pellucida (Trounson \& Moore, 1974). However, the technique of agar embedding, followed by culture in the ligated sheep oviduct, has provided a solution to this problem (Willadsen, 1979a). This procedure has already proved effective for the study of developmental potential of isolated blastomeres from cleaving embryos of the large domestic species (Willadsen, 1980; Willadsen \& Polge, 1981). The present report describes experiments in which the same general methods were used with the aim of establishing a routine procedure for the production of sheep chimaeras by blastomere aggregation. 


\section{Materials and Methods}

The techniques used for superovulation, synchronization of oestrus, insemination, embryo collection and embryo transfer were those described by Willadsen (1979b). Parent embryos of the following breed combinations were used as blastomere donors: Suffolk $\times$ Suffolk, Welsh Mountain $\times$ Suffolk, Welsh Mountain-Suffolk $\times$ Suffolk, Jacob $\times$ Suffolk, Welsh Mountain $\times$ Finn, Blackface $\times$ Finn, Jacob $\times$ Finn, Clun Forest $\times$ Finn, Welsh Mountain $\times$ Welsh Mountain, Blackface $\times$ Welsh Mountain and Welsh Mountain $\times$ Dalesbred. Welsh Mountain, Suffolk and Welsh Mountain-Suffolk ewes were used as recipients. Proven infertile vasectomized Welsh Mountain rams were used for detection of oestrus in the ewes.

The parent embryos were collected at the 2-, 4- or 8-cell stage. A phosphate-buffered saline medium (PBS: Whittingham, 1971) was used for recovery, storage and transfer of embryos and also for holding embryos and blastomeres during the various manipulations. The general micromanipulative procedures were the same as those used in previously reported experiments with sheep blastomeres (Willadsen, 1980), with the following modifications: completely dissociated blastomeres from two or more parent embryos at the same stage of development were inserted into the evacuated zona pellucida of a follicular pig oocyte (when the total cell number was equal to, or less than, that of an ordinary embryo), or into the zona pellucida from a fully expanded pig blastocyst (when the total cell number was twice or three times that of an ordinary embryo). When the total cell number was 4 or 8 times that of an ordinary embryo, the dissociated blastomeres were placed in a pre-formed spherical cavity $(\sim 0.3 \mathrm{~mm}$ in diameter $)$ in a cylinder $(0.4 \times 0.6 \mathrm{~mm})$ of $1.2 \%$ agar. Composite embryos that were contained in zonae pellucidae were embedded in small cylinders $(0.2 \times 0.5 \mathrm{~mm})$ of $1 \%$ agar. These cylinders and those containing denuded blastomeres were embedded in larger ones $(\sim 0.8 \times 1.5-2.0 \mathrm{~mm})$ of $1.2 \%$ agar.

The agar 'chips' containing the composite embryos were transferred to the ligated oviducts of ewes on Days 2-9 of the oestrous cycle (day of onset of oestrus = Day 0 ) and were collected 4 or 5 days later, depending on the stage of development of the parent embryos. After recovery from the temporary recipients, the embryos were examined as fresh specimens, and those that had developed into properly organized blastocysts were transferred to ewes on Day 6 or 7 of the oestrous cycle. Recipient ewes that did not return to oestrus were allowed to go to term. The lambs were examined for external signs of chimaerism, and those surviving at 60 days were blood typed. The donor ewes and the fertile rams used in the experiments were also blood typed.

All blood samples were examined for the following polymorphic features as described by Tucker et al. (1974) and Tucker (1975).

Red blood cell antigens: the antigen types possible at the loci designated $A, B, C, D, M, R$, and V. Haemolytic tests were used.

Red blood cell proteins: haemoglobin, malic enzyme, NADH-diaphorase, carbonic anhydrase, nucleoside phosphorylase and ' $\mathrm{X}$ ' protein. Different forms of each protein were separated by starch gel electrophoresis.

Plasma proteins: albumin, transferrin and esterase. Different types of albumin and transferrin were separated by starch gel electrophoresis. Plasma samples were classified as A-esterase positive or negative by means of a simple spot test.

A lamb was judged to be a chimaera if it (a) exhibited clear external signs of chimaerism, and/or (b) had a blood type which could not have been derived from any single parent embryo or (c) had a nonchimaeric blood type corresponding to one parent embryo while being of a physical appearance corresponding to another parent embryo.

\section{Results}

A total of 110 composite embryos of cell numbers ranging from one quarter of the normal cell number to 8 times the normal number were produced (Table 1). Each composite embryo consisted of an equal number of blastomeres derived from 2-8 parent embryos, all at the same stage of 
development. The 33 agar 'chips' containing composite embryos were transferred to the ligated oviducts of 19 temporary recipients: 30 of the 'chips', containing $101(91.8 \%)$ embryos, were subsequently recovered and $77(76.2 \%)$ of the embryos had continued to develop at the normal rate and had formed normally organized blastocysts.

All the 9 categories of composite embryos were represented among the chimaeric blastocysts (Table 1). Those that had developed from composite embryos consisting of the normal number of cells, or less, were morphologically indistinguishable from non-chimaeric blastocysts produced from the same number of blastomeres (Willadsen, 1980, 1981). Those that had developed from more than the normal number of blastomeres were larger than ordinary sheep blastocysts, and had very large, prominent inner cell masses. In two of these giant blastocysts, both produced from 4 times the normal number of blastomeres, two inner cell masses were observed.

Table 1. The development of composite sheep embryos produced by aggregation of various numbers of blastomeres from two or more parent embryos at the 2- to 8-cell stage

\begin{tabular}{|c|c|c|c|c|c|c|c|c|c|c|}
\hline & \multicolumn{9}{|c|}{ Composition of embryos } & \multirow[b]{2}{*}{ Total } \\
\hline & $\frac{1}{8}+\frac{1}{8}$ & $\frac{1}{4}+\frac{1}{4}$ & $4 \times \frac{1}{8}$ & $\frac{1}{2}+\frac{1}{2}$ & $8 \times \frac{1}{8}$ & $8 \times \frac{2}{8}$ & $3 \times \frac{8}{8}$ & $4 \times \frac{8}{8}$ & $8 \times \frac{8}{8}$ & \\
\hline \multirow{3}{*}{$\begin{array}{l}\text { No. transferred to } \\
\text { temporary recipients } \\
\text { No. recovered from } \\
\text { temporary recipients } \\
\text { No. of well-integrated } \\
\text { blastocysts }\end{array}$} & 21 & 32 & 13 & 5 & 4 & 9 & 5 & 19 & 2 & 110 \\
\hline & 18 & 28 & 13 & 5 & 4 & 9 & 5 & 17 & 2 & 101 \\
\hline & 16 & 15 & 11 & 5 & 4 & 8 & 4 & 12 & 2 & 77 \\
\hline definitive recipients & 10 & 15 & 11 & 5 & 4 & 8 & 4 & 15 & 2 & 74 \\
\hline No. of full term lambs & 5 & 10 & 9 & 3 & 4 & 6 & 1 & 13 & 2 & 53 \\
\hline $\begin{array}{l}\text { No. blood typed } \\
\text { No. of chimaeras }\end{array}$ & 3 & 10 & 9 & 3 & 4 & 6 & 0 & 13 & 0 & 48 \\
\hline (overt and/or blood) & 0 & 5 & 6 & 3 & 4 & 6 & - & 12 & $\cdots$ & 36 \\
\hline
\end{tabular}

$\frac{1}{8}$ denotes one blastomere from an 8-cell embryo; $\frac{1}{4}$ denotes one blastomere from a 4-cell embryo; $\frac{1}{2}$ denotes one blastomere from a 2 -cell embryo; $4 \times \frac{1}{8}$ denotes 4 blastomeres each from a different 8 -cell embryo; $\frac{2}{8}$ denotes 2 blastomeres from a single 8 -cell embryo; $8 \times \frac{2}{8}$ denotes 8 pairs of blastomeres from 8 different 8 -cell embryos; $3 \times \frac{8}{8}$ denotes aggregation of three 8-cell embryos.

Seventy-four chimaeric blastocysts were transferred to 51 recipient ewes: $38(74.5 \%)$ of the recipients went to full term, producing a total of 53 lambs, corresponding to $71.6 \%$ of the embryos transferred. All 9 categories of composite embryos were represented among the lambs. One ewe that had received a single embryo of 4 times the normal cell number gave birth to twins, although only one inner cell mass had been observed in this embryo before transfer. Another ewe, which had received an embryo with two inner cell masses, aborted a single (overtly chimaeric) fetus on Day 121 (normal gestation length $\sim 146$ days).

Abnormalities which were not immediately recognizable as the results of chimaerism were observed in two lambs. One of these, which had developed from an embryo of 3 times the normal cell number, was born with facial malformations and was killed immediately after birth. The other, which had developed from an embryo of 8 times the normal cell number, had bilateral hydronephros accompanied by hydroallantois. This lamb was delivered dead by Caesarean section.

Of 48 lambs that survived to be blood typed, 20 had developed from composite embryos produced from parent embryos of the same breeding, and thus could not be expected to exhibit overt chimaerism. However, 16 of these animals had chimaeric blood types. Amongst the 28 lambs that had developed from composite embryos produced from parent embryos of differing breeding, 12 were overt chimaeras (PI. 1, Fig. 1), of which 10 were also demonstrated to be blood chimaeras. Of the remaining 16 animals, which were not overt chimaeras, 7 had chimaeric blood types, and 
one derived its external features from one parent embryo, while it had unique blood features derived from another parent embryo.

Altogether therefore, $36(75 \%)$ of the 48 lambs were demonstrated to be chimaeric. Among these were $25(96 \%)$ of the 26 lambs that had developed from composite embryos of the normal number of cells, or more, while only $11(50 \%)$ of the 22 lambs that had developed from composite embryos of less than the normal cell number were judged to be chimaeras. Twenty-six of the chimaeras were phenotypically male, 1 was an intersex, and 9 were phenotypically female. Of the non-chimaeric lambs, 7 were male, 5 female.

\section{Discussion}

The results of this study confirm that blastomeres isolated from early cleavage stages in the sheep have the same ability as mouse blastomeres to form chimaeric blastocysts after being aggregated. In the present experiments, the timing and general pattern of blastulation in composite embryos was the same as in ordinary sheep embryos, irrespective of the number of cells and the number of contributing parent embryos. However, the total cell number, and the proportion of cells allocated to the inner cell mass, depended on the initial cell number. Thus blastocysts that were produced from two single blastomeres from two 8-cell embryos were not only considerably smaller than ordinary sheep blastocysts, but also had disproportionately smaller inner cell masses. The same pattern was evident, to a lesser extent, in blastocysts produced from composite embryos with half the normal number of cells. With the reduction in the number of cells allocated to the inner cell mass the chance that all of these cells are derived from a single parent blastomere must be increased. It is therefore not surprising, but nevertheless interesting, that relatively few of the lambs produced from chimaeric 'quarter' and 'half' embryos were chimaeras. On the other hand, chimaeric blastocysts produced from composite embryos of a larger than normal number of cells were not only larger than ordinary sheep blastocysts, but had disproportionately larger inner cell masses. There should therefore be a greater chance that the inner cell mass contained cells derived from different parent embryos and, hence, a large proportion of the lambs produced from such giant blastocysts could be expected to be chimaeras, as indeed was the case.

The formation of two inner cell masses, instead of a single one, in some of these giant embryos could be the result of a failure of two or more primary centres of blastulation to coalesce before the accumulation of blastocoelic fluid had already moved large groups of inner cells too far apart for them to be incorporated into the same inner cell mass. The twin lambs that were produced from a single chimaeric blastocyst of 4 times the normal cell number (Pl. 1, Fig. 2) may have developed from two separate inner cell masses. However, this seems unlikely, both because only one inner cell mass was observed in the blastocyst before it was transferred, and because these two animals were

\section{PLATE 1}

Fig. 1. Overtly chimaeric ram produced by combining one blastomere from a Welsh Mountain 4-cell embryo with one blastomere from a Welsh Mountain $\times$ Suffolk embryo. The patchy grey colour markings are derived from the latter parent embryo while the black background colour of the fleece is derived from the purebred Welsh Mountain embryo.

Fig. 2. Twin lambs which developed from a single chimaeric blastocyst produced by combining all the dissociated blastomeres from four 8-cell embryos of sheep of the following breedings: (a) Welsh Mountain $\times$ Welsh Mountain, (b) Suffolk $\times$ Suffolk, (c) Jacob $\times$ Finnish Landrace, and (d) Blackface $\times$ Welsh Mountain. The 2 lambs had blood types which were both qualitatively and quantitatively identical, and implicated parent embryos (a), (b) and (c). The animals were also of identical physical appearance except that in one the left ear was longer than the right ear, while in the other the right ear was longer than the left. 
PLATE 1

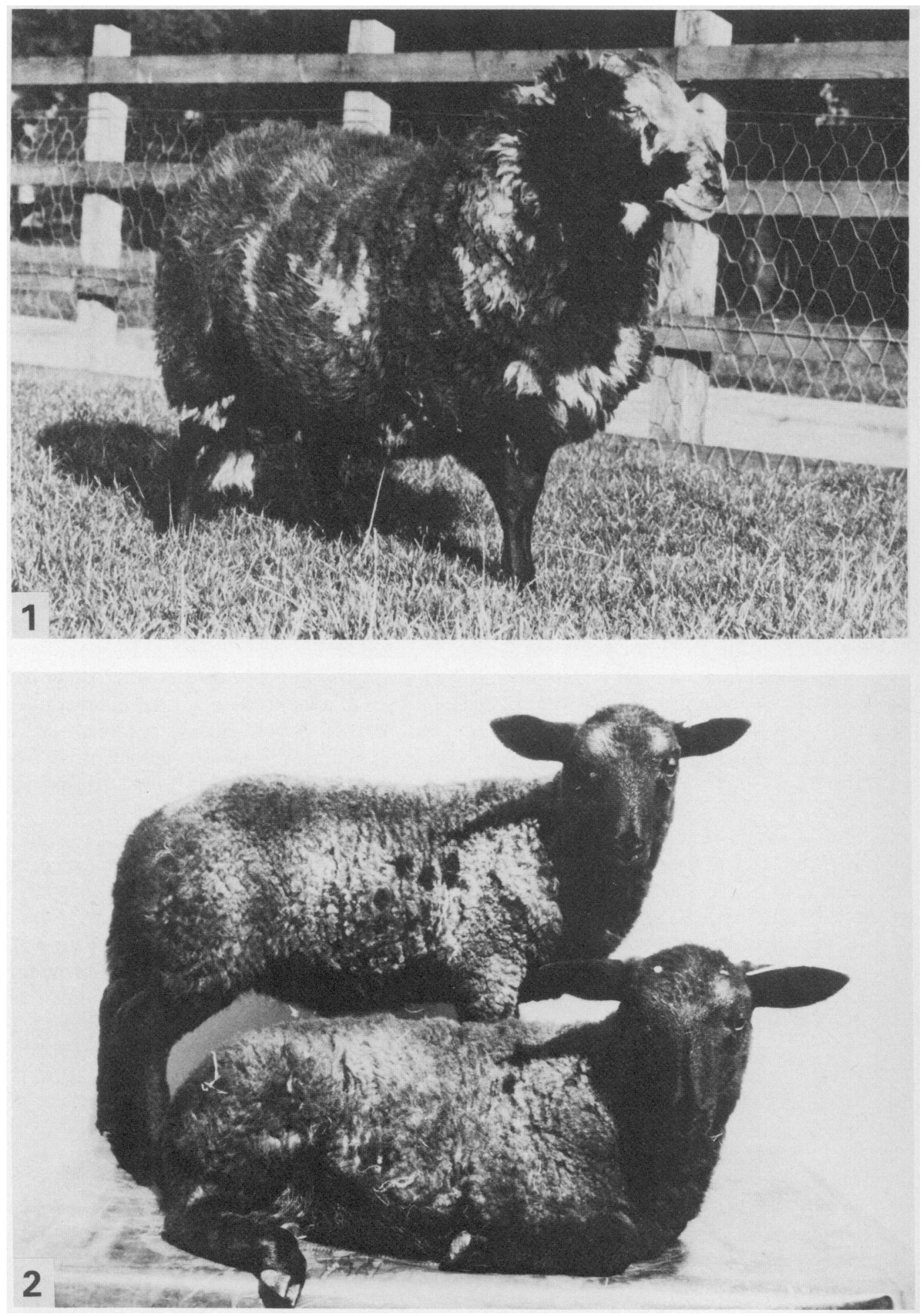

(Facing p. 350) 
nearly identical (both qualitatively and quantitatively) in blood type as well as in physical appearance. It may therefore be that, in this instance, twinning was the result of events subsequent to the formation of the inner cell mass.

The number of contributing parent embryos per se did not appear to have any adverse influence on the viability of the composite embryo (see Table 1). In most instances in which composite embryos consisted of blastomeres from more than two parent embryos, the parent embryos were from the same donor ewe, and although it was possible to demonstrate whether the lambs developing from these were chimaeric, no attempt was made to determine how many of the parent embryos had contributed directly to the formation of the fetus. However, 4 of the composite embryos of 4 times the normal number of cells were produced from parent embryos of 4 different breedings, and 3 of the 5 lambs produced had blood types which implicated 3 parent embryos.

The results of this study clearly show that agar embedding followed by culture in vivo is an effective procedure for the production of chimaeric sheep blastocysts and, therefore, chimaeric sheep, from aggregated blastomeres. This procedure is more complex and laborious than the method used in the production of mouse aggregation chimaeras. In the mouse, the zona-free embryos are simply placed in close apposition and a single aggregate is formed during subsequent culture in vitro. With the present technique, a greater degree of cell mixing may be achieved as the blastomeres are completely dissociated before being aggregated. Therefore this method is probably more effective and in addition more versatile than methods relying on simple aggregation of denuded embryos.

The ligated sheep oviduct offers an adequate environment, not only for sheep embryos at stages of development ranging from 1 cell to hatched blastocysts (Day 9), but also for corresponding stages of development in the other domestic species. Indeed, goat and cow chimaeras have now been produced by the procedures used in the present study (C. B. Fehilly \& S. M. Willadsen, unpublished results).

\section{References}

McLaren, A. (1976) Mammalian Chimaeras. Cambridge University Press.

Mintz, B. (1971) Allophenic mice of multi-embryo origin. In Methods in Mammalian Embryology, pp. 186-214. Ed. J. C. Daniel, Jr. W. H. Freeman, San Francisco.

Pighills, E., Hancock, J.L. \& Hall, J.G. (1968) Attempted induction of chimaerism in sheep. J. Reprod. Fert. 17 , 543-547.

Tarkowski, A.K. (1961) Mouse chimaeras developed from fused eggs. Nature, Lond. 190, 857-860.

Trounson, A.O. \& Moore, N.W. (1974) The survival and development of sheep eggs following complete or partial removal of the zona pellucida. J. Reprod. Fert. 41, 97-105.

Tucker, E.M. (1975) Genetic markers in the plasma and red blood cells. In The Blood of Sheep, pp. 123-153. Ed. M. H. Blunt. Springer-Verlag, Berlin.

Tucker, E.M., Moor, R.M. \& Rowson, L.E.A. (1974) Tetraparental sheep chimaeras induced by blastomere transplantation. Changes in blood type with age. Immunology 26, 613-621.
Whittingham, D.G. (1971) Survival of mouse embryos after freezing and thawing. Nature, Lond. 233, 125 126.

Willadsen, S.M. (1979a) A method for culture of micromanipulated sheep embryos and its use to produce monozygotic twins. Nature, Lond. 277, 298-300.

Willadsen, S.M. (1979b) Embryo transplantation in sheep. In The Management and Diseases of Sheep, pp. 69-85. Commonwealth Agricultural Bureau, Farnham.

Willadsen, S.M. (1980) The viability of early cleavage stages containing half the normal number of blastomeres in the sheep. J. Reprod. Fert. 59, 357-362.

Willadsen, S.M. (1981) The developmental capacity of blastomeres from four- and eight-cell sheep embryos. J. Embryol. exp. Morph. 65, 165-172.

Willadsen, S.M. \& Polge, C. (1981) Attempts to produce monozygotic quadruplets in cattle by blastomere separation. Vet. Rec. 108, 211-213.

Received 13 July 1983 